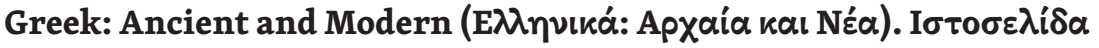

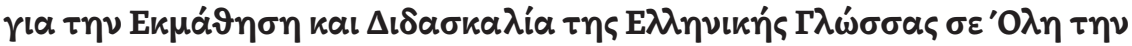

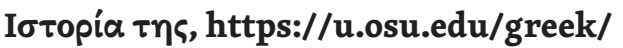

Jerneja Kavčič

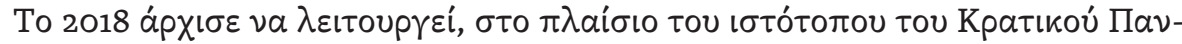

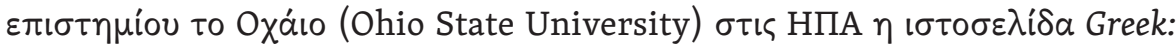

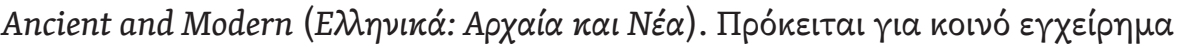

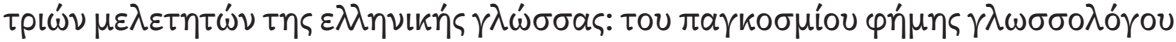

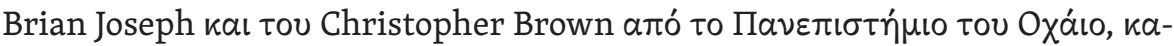

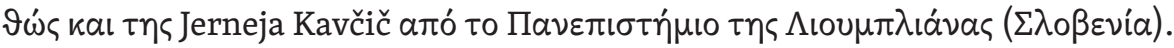

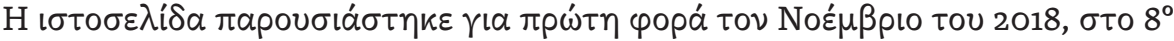

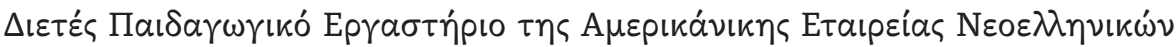

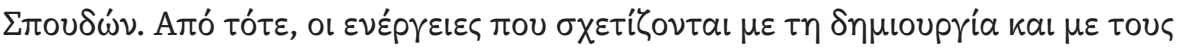

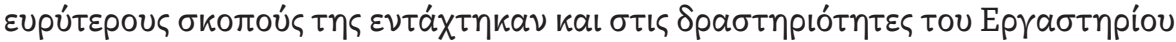

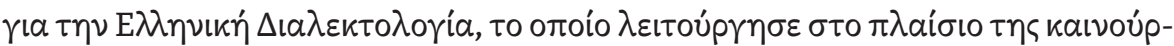

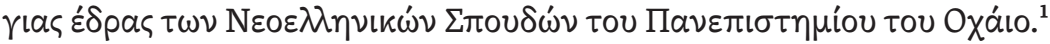

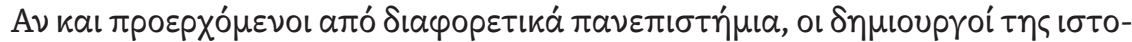

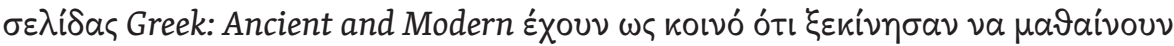

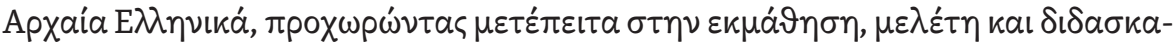

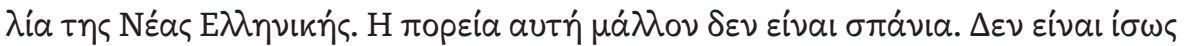

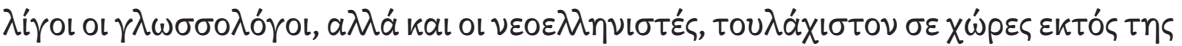

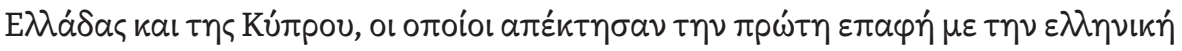

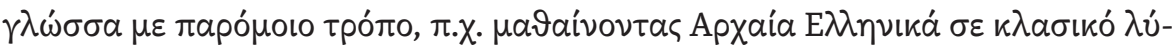

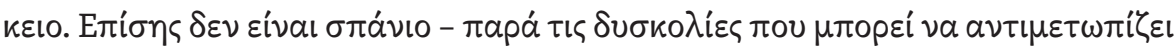

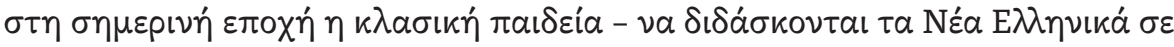

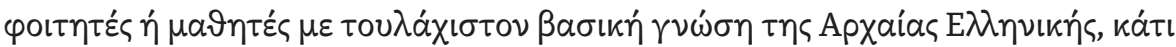

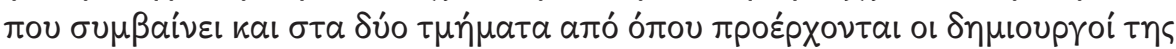

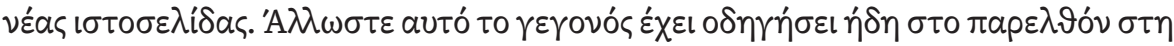

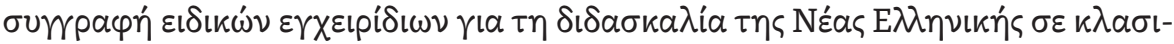

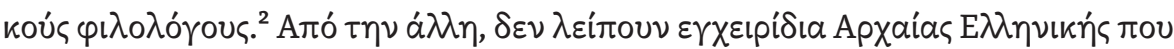

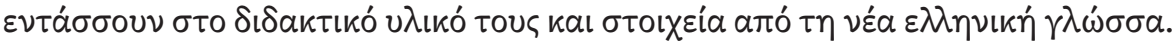

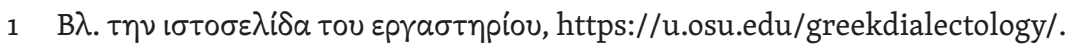

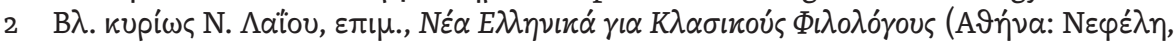

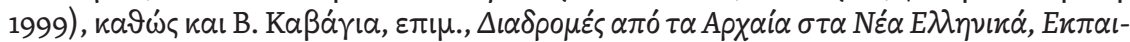

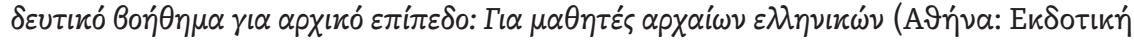
'A $\lambda \varphi \alpha, 2009)$. 


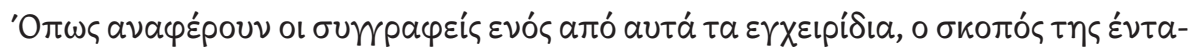

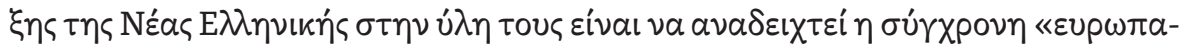

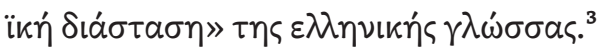

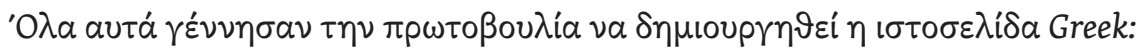

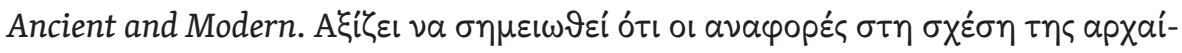

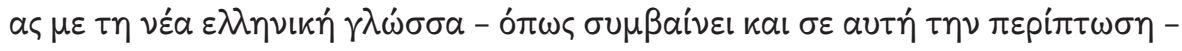

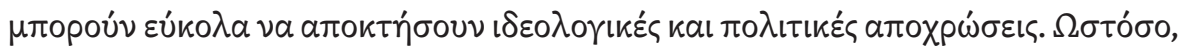
$\pi \varepsilon ́ p a$ a

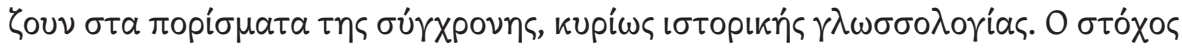

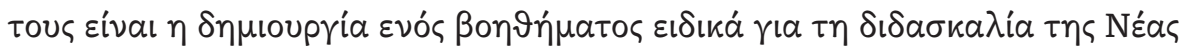

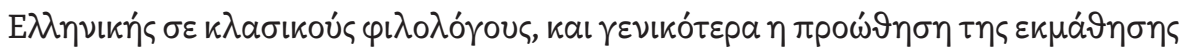

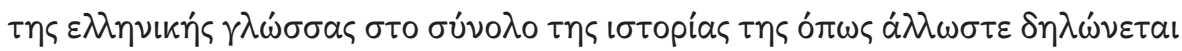

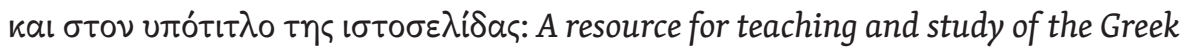
language in all its phases.

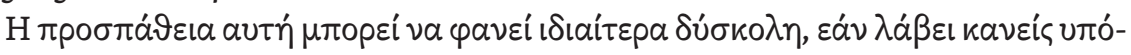

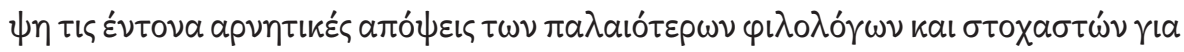

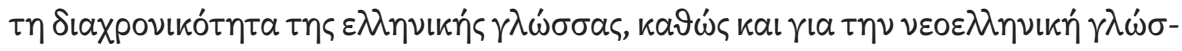

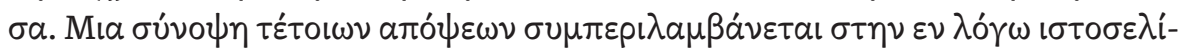

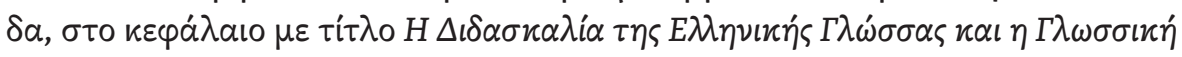

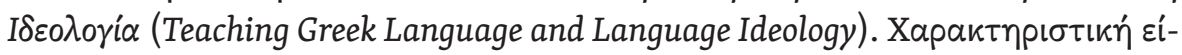

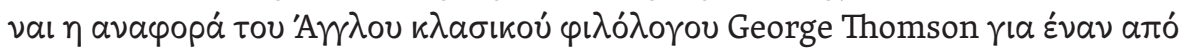

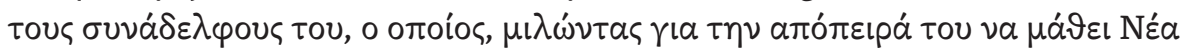

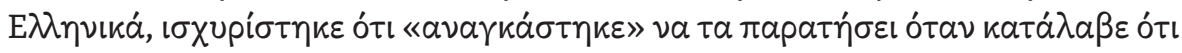

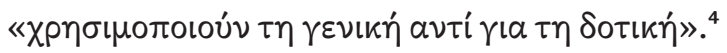

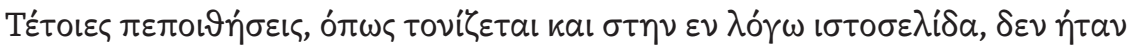

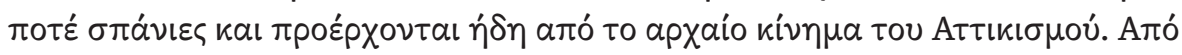

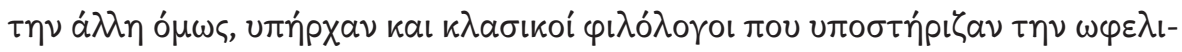

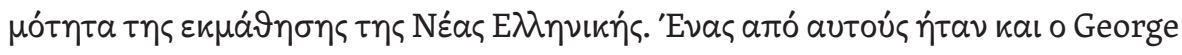

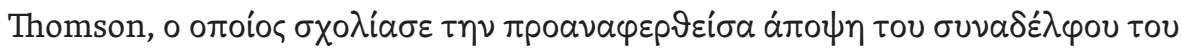

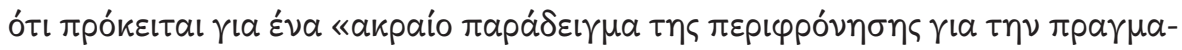

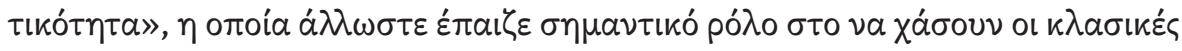

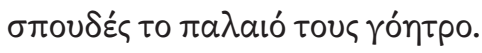

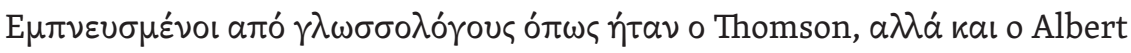

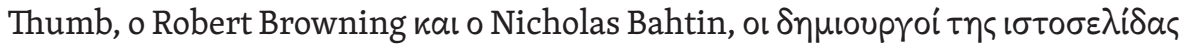

3 A. Weileder \& H. Mayerhöfer, $\varepsilon \pi \uparrow \mu$., Kairos: Griechisches Unterrichtswerk (Bamberg: Buchners Verlag, 2013), 4.

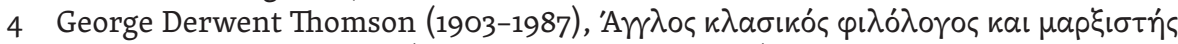

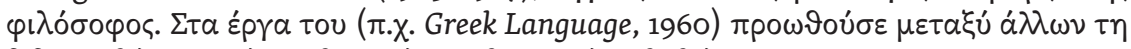

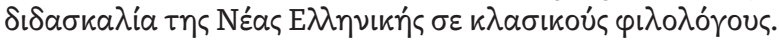




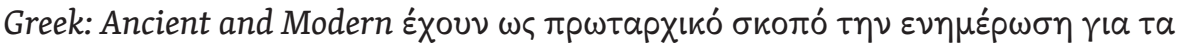

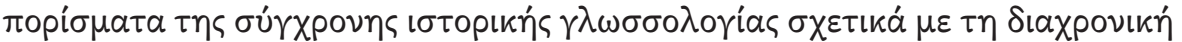

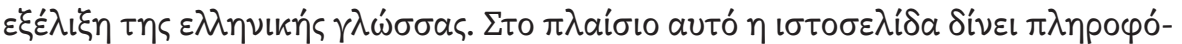

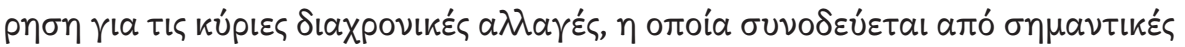

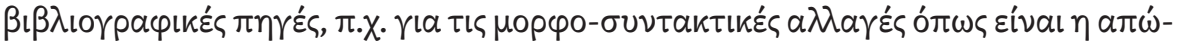

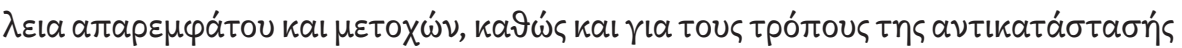

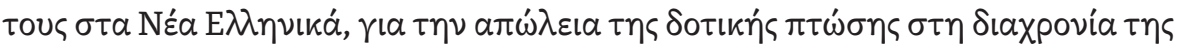

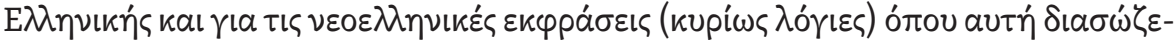

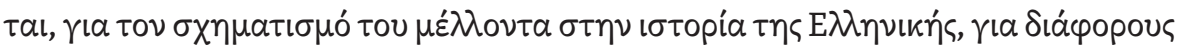

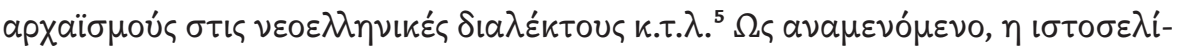

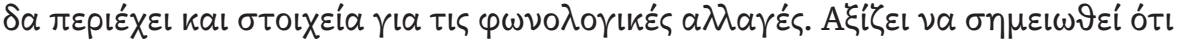

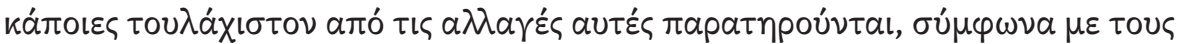

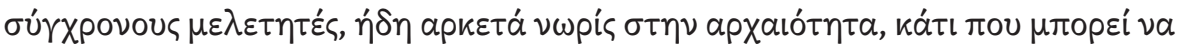

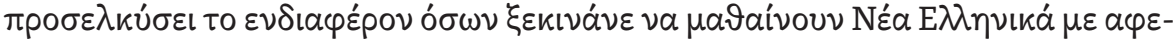

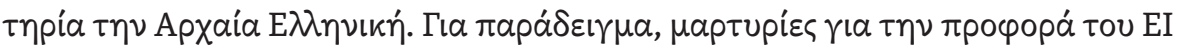

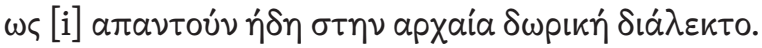

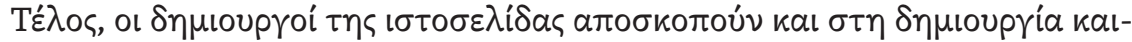

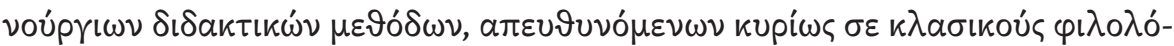

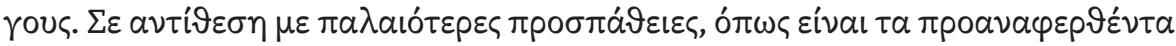

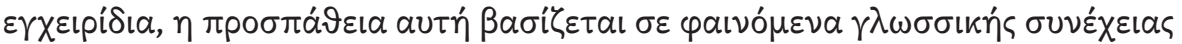

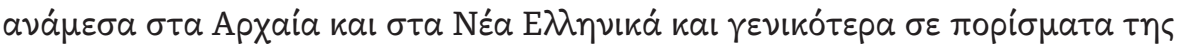

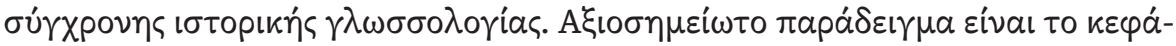

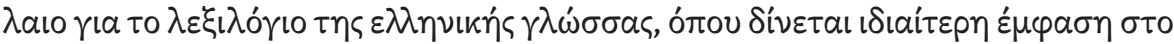

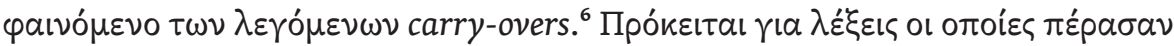

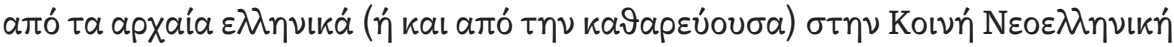

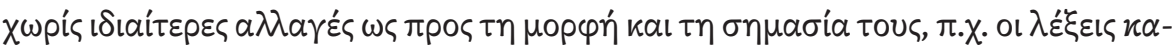

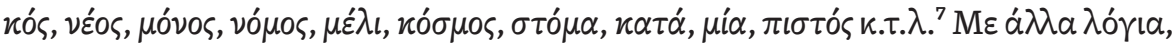

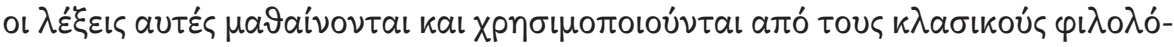

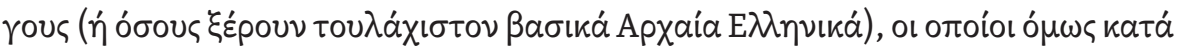

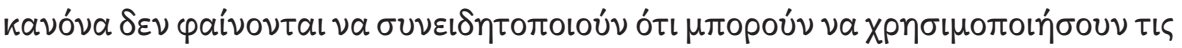

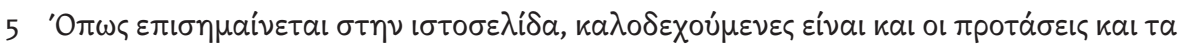

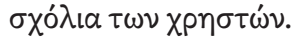

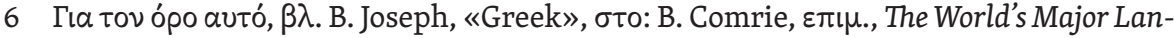
guages (New York: Routledge, 2009), 369.

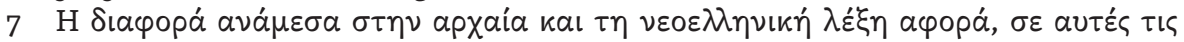

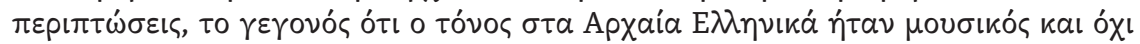

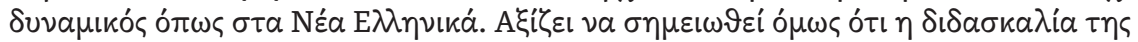

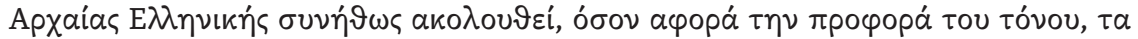

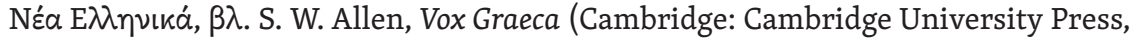
1974), 136. 


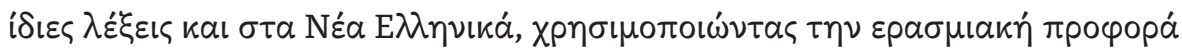

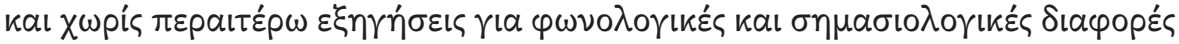

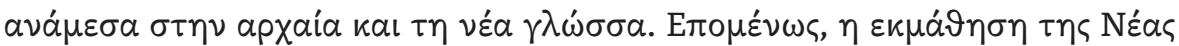

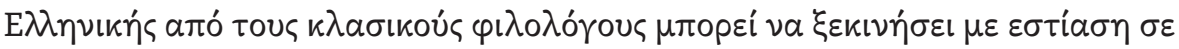

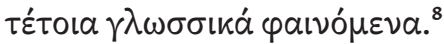

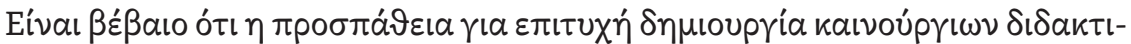

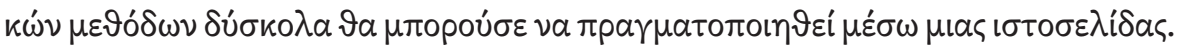

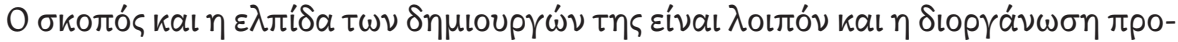

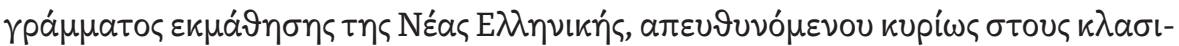

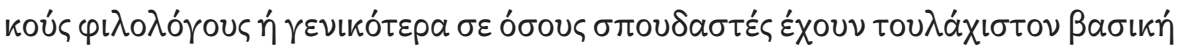

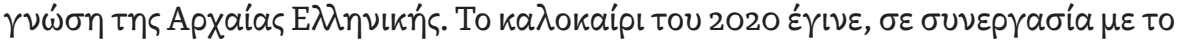

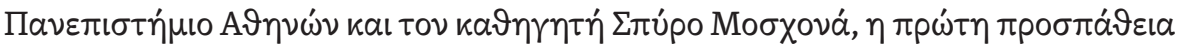

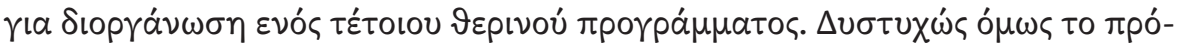

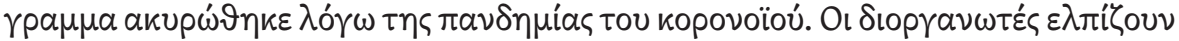

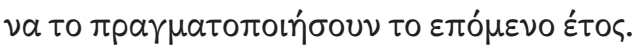

\section{Projekt Erasmus+ na podporu výuky novořečtiny}

Simone Sumelidu

Ve stanovách České společnosti novořeckých studií stojí: „... hlavní náplní činnosti společnosti je podpora vědeckého studia a výuky novořeckého jazyka.“ Právě výuku novořečtiny v České republice jsme se rozhodli podpořit prostřednictvím projektu „Zvyšování didaktické kvalifikace a akreditace členů České společnosti novořeckých studií“. Jak prozrazuje název, zaměřili jsme se na učitele řeckého jazyka, cílem projektu bylo zvýšit jejich dovednosti v oblasti metodiky a didaktiky novořečtiny a zlepšit tak jejich pedagogické kompetence.

Projekt byl schválen $v$ rámci vzdělávacího programu Erasmus+ zaměřeného na spolupráci a mobilitu v oblasti vzdělávání, v klíčové akci KA1 Vzdělávací

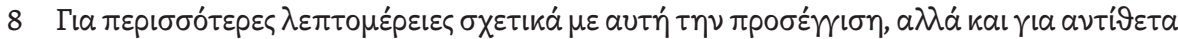

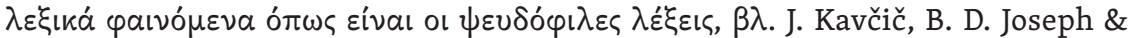
C. Brown, «Teaching Modern Greek to Classicists: Taking Advantage of Continuity», Keria: Studia Latina et Graeca 22, 2 (2020). 